\title{
Journal of Scientific Research
}

Vol. 1, Issue 2, 1 May 2009

\section{Announcements}

Publication charge: Currently there is no publication charge from the authors (applicable to issues 1, 2 and 3 of volume 1). Authors get copies of published articles free of charge from the journal web site www. banglajol.info/index.php/JSR, but they have to register for that.

A modest publication charge of accepted articles (does not include Reprints) to defray the partial cost of journal printing is applicable for accepted articles of volume 2 and onwards - authors will get notification for that at appropriate time after acceptance of their articles. The rate varies from US\$ 5 to $\$ 10$ (or Tk 300) per page of accepted paper depending on author's geographical locations. The publication charge will apply to papers that are accepted for publication in volume 2 and onwards. Method of payment at present is via bank draft. Information for electronic transfer will be announced later on.

Draft payable to: Editor-in-Chief, Journal of Scientific Research (Address: Faculty of Sciences, Rajshahi University, Rajshahi-6205, Bangladesh).

\section{Some useful information for Authors:}

1. MS Preparation: Consult "Author Guidelines and Example Article" (vol. 1, issue 1) for preparing articles in MS Word only. May also see any published paper in JSR for style and figure, table sizes etc.

2. Submission: Two methods of submission:

a. Web submission: This is the preferred method of submission - authors are encouraged to use this method. Website: www.banglajol.info/index.php/JSR

Complete 5 step processes. For multi-authored manuscript, submit information of all the co-authors during initial submission.

b. E-mail submission: For multi-authored manuscript, supply e-mails of all the coauthors.

It is recommended that the authors should make PDF file of their manuscripts to test that everything (Fig., Table, Equations etc.) is reproduced correctly.

3. Publication schedule: Frequency 3 issues per year as follows:

Issue 1: $1 \mathrm{~J}$ anuary

Issue 2: 1 May

I ssue 3: 1 September

\section{Steps in the process of MS handling:}

\section{a. Acknowledgement of submission.}

Auto generated reply with MS ID for web submission.

MS ID is allocated and acknowledged by e-mail by the editor for e-mail submission.

b. Peer-review process: Usually takes 2 to 3 months.

c. Editorial decision: Author is informed as soon as a decision is made upon receipt of reviews. 